\section{Impactos da Cultura na Economia da Bahia: participação no gasto turístico e consumo de residentes e governo}

\section{Grazia Burman}

RESUMO: Trata de aspectos importantes da produção e consumo cultural, medindo os impactos na economia, através de metodologia de cálculo do Produto Interno Bruto (PIB) Cultural. O PIB da cultura, que em 1996 correspondeu a $4,4 \%$ do PIB da Bahia, revelou a impor tância dessa indústria na geração de emprego e renda, na participação no gasto turístico, no consumo de residentes e do governo.

PALAVRAS-CHAVE: Cultura; economia; Bahia, Brasil.

ABSTRACT: This study presents important cultural production and consuming aspects in the economy of BahiaState. The metodology used, considered the impact of cultural gross domestic product, which represented in $1966-4,4 \%$ of the total gross domestic product of Bahia State. The incremental of tourism activitie in these areas provided a substancial improvements of life condictions for local residents and government income through new jobs generation and local consuming in crease.

KEYWORDS: Tourism and economy; cultural impacts; grossdomestic product; tourismand residentsconsuming; Bahia; Brazil.

\section{Introduçāo}

Acompanhando uma tendência global, o setor públicovive hoje um processo de transição em que suas ações voltam-se, crescentemente, para os aspectos sociais e para o campo normativo e indutor da atividade econômica. Em contrapartida, o setor privado nacional e internacional vêm assumindo papel mais ativo na promoção do crescimento, a partir de investimentos produtivos, num momento em que a importância de relações articuladas parece ser a perspectiva que poderá solucionar os desequilíbrios regionais e sociais.

Com esta compreensão, a Secretaria da Cultura e Turismo (SCT) da Bahia dirigiu os esforços para a pesquisa e mensuração dos impactos da cultura na economia do Estado, visando, dessa forma, a implantação de um sistema de agregados macroeconômicos que possibilite identificar um indicador sintético, como é o PIB, acompanhando seu principal vetor de expansão "o consumo das famílias residentes e não-residentes", avaliando o perfil do consumidor e, assim, capacitando-se a direcionar o planejamento estratégico governamental e empresarial.

Este sistema vai permitir o acompanhamento do setor através dos investimentos realizados pelas empresas privadas e pelo governo, do consumo das famílias e do governo ou consumo coletivo, bem como mensurar o produto gerado pelas empresas privadas, a geração de empregos, a composição do valor agregado bruto e, ainda, estimar o valor das exportações de produtos culturais, assim como o das importações.

A cultura tem sustentado boa parcela dos empregos na Região Metropolitana de Salvador (RMS). Mais de 50\% da mão-de-obra ocupadaencontra-se no setor de serviços, com o que, agregando-se o comércio, têm-se aproximadamente $78 \%$ dos ocupados da RMS. Assim, entre as 1.087 .100 pessoas ocupadas, segundo a Pesquisa Nacional por Amostra de Domicílios - PNAD (1996), aproximadamente 853 mil estão no mercado de trabalho ligadas ao setor terciário da economia.

\section{Metodologia}

A Contabilidade Nacional é uma técnica que tem por objetivo representar e quantificar a economia de um país. $\mathrm{O}$ esquema descritivo visa reproduzir os fenômenos essenciais do circuito econômico: produção, geração de renda, consumo, financiamento, acumulação e relações com o resto do mundo. Como todo esquema descritivo é, também, uma simplificação da realidade.

Este consumo, enquanto Sistema de Contabilidade Social, é mensurado a partir do total consumido a preços de mercado pelas famílias residentes e nãoresidentes, permitindo, dessa forma, a mensuração da produção cultural pela ótica da despesa, agregando-se a este consumo: o consumo coletivo (do governo), o investimento público, as instituições sem fins lucrativos e empresas privadas, a Matemática e especialista em Modelos Lineares pela USP. Professora de Estatística de Turismo na UNIFACS/BA, e
de Econometria na Universidade Católica de Salvador. Assessora da Secretaria da Indústria, Comércio e Turismo da

End : Av Luis Viana Filho, s/n-40030-010-Salvador - Bahia 
variação de estoques, e as exportações menos as importações.

Metodologicamente, calculando-se o PIB pela ótica da despesa, tem-se

\begin{tabular}{c} 
CONSUMOFINAL \\
$(+)$ \\
FORMAÇĀO BRUTA DE CAPITAL FIXO \\
$(+)$ \\
PIB $=\quad(+)$ \\
VARIAÇĀO DE ESTOQUES \\
$(+)$ \\
EXPORTAÇŌES \\
$(-)$ \\
MPPORTAÇŌES \\
\hline
\end{tabular}

Mantendo-se a igualdade pela ótica da produção:

\begin{tabular}{cc}
\hline VIB $=$ & VALOR BRUTO DE PRODUÇĀO \\
$(-)$ & $(-)$ \\
& CONSUMOINTERMEDIÁRIO \\
\hline & \\
\hline & REMUNERAÇĀO DO TRABALHO \\
$(+)$ & \\
& EXCEDENTE OPERACIONAL BRUTO \\
$(+)$ & \\
& IMPOSTOS - SUBSIDIOS \\
\hline
\end{tabular}

\section{O Período da Estimativa - 1996}

O ano de 1996 foi o período escolhido para a estimativa do PIB da cultura, decidindo-se iniciar por este período pelo fato do mesmo apresentar a avaliação mais próxima da Pesquisa de Gastos que estava sendo realizada (1997) e por coincidir com o ano da Pesquisa de Gastos dos "não-residentes" (1996), e das informações da PNAD (1996), de onde foram retirados os dados de massa de rendimentos das famílias e ocupações.

O percentual ou impacto do PIB da cultura sobre o PIB da Bahia considerou o valor em dólares deste último indicador calculado pela Superintendência de Estudos Econômicos e Sociais da Bahia (SEI), que já dispunha destes resultados.

\section{Abrangência}

Sabendo-se que existe uma predisposição maior a consumir produtos culturais na RMS, principalmente em Salvador em virtude da urbanização e da concentração de produtos e serviços ligados à cultura nessa região, as medidas de gastos são usualmente realizadas na RMS, a exemplo da Pesquisa de Orçamento Familiar (POF) realizada pelo IBGE. Medidas deste tipo supõem que a expansão dos resultados seja possível somente para regiões urbanas.

Contudo, como se deseja uma medida de comparabilidade da cultura com os demais agregados macroeconômicos do Estado, vale que o esforço de mensuração através de estimativas possa permitir esta mensuração. Assim, procedeu-se à expansão das estimativas da cultura, resultando no Produto Interno Bruto da Cultura na Bahia.

\section{Resultados - Principais Estimativas}

\section{Pessoas Ocupadas em Atividades Relacionadas à Cultura na RMS}

No conjunto de atividades vinculadas à cultura, entre as quais figuram os escritores e críticos, jornalistas, coreógrafos e bailarinos, artistas, ambulantes em festas de largo, nas festas do Carnaval e São João, museólogos, baianas de acarajé, pôde-se realizar, através de pesquisa direta, uma sondagem que determinou a participação desse mercado formal e informal na cidade de Salvador.

Através da Pesquisa Direta, constatou-se que 7,2\% dos ocupados com rendimentos haviam realizado atividades relacionadas à cultura no ano de 1996, e que esse contingente poderia ser estimado em 84.350 pessoas na RMS. A caracterização de informalidade deste emprego ficou constatada pelo número de dias médios trabalhados realizado durante o ano de 1996, de aproximadamente 58 dias, o que caracteriza o emprego temporário e o vínculo de informalidade dessas ocupações.

\section{Consumo dos Não-Residentes}

Pesquisa realizada entre janeiro e fevereiro de 1996 identificou que o consumo de produtos de diversão, realizado pelo turista em Salvador, correspondia a $12,7 \%$ do total do gasto diário, a compra de artesanato e outros equivaliam a $18,6 \%$. Poder-se-ia dizer que aproximadamente $31 \%$ dos gastos dos consumidores não-residentes eram realizados com produtos estritamente culturais, e que, certamente, outros gastos realizados estariam ligados ao consumo de cultura.

Uma estimativa desse consumo, considerando-se a receita do turismo da Bahia, em 1996, estimada pela BAHIATURSA (US\$ 660 milhões), permitiria afirmar que o consumo dos não-residentes com cultura se aproximaria de US\$205 milhões ao ano ou $\mathrm{R} \$ 212$ milhões.

CONSUMO DOS NĀO-RESIDENTES RS 212 milhōes 


\section{Consumo das Familias Residentes}

Na Pesquisa de Orçamento Familiar, instrumento de avaliação do gasto das famílias na RMS, realizada em 1988 pelo IBGE, encontrou-se um consumo familiar médio em educação e divertimento de $3,20 \%$ do orçamento familiar, estando os outros gastos com cultura identificados como livros $(0,14 \%)$, revistas $(0,20 \%)$, equipamentos fotográficos $(0,03 \%)$, livros escolares e técnicos $(0,18 \%)$, discos e fitas $(0,16 \%)$ e jornais $(0,38 \%)$. Outros itens do consumo familiar poderiam, entretanto, ser incorporados ao consumo de cultura, mas o que chama atenção nesta pesquisa realizada em 1988, quando comparada à anterior, 1974, e que foi identificado por Borges e Burman (1992), são os novos hábitos de consumo.

Finalmente espelhando sobretudo as mudanças nos padrōes do lazer urbano e a ampliação do consumo de produtos da chamada "indústria cultural", em todas as faixas de renda, ocorre um aumento de $2,2 \%$ para $3,8 \%$ na participaçāo relativa das despesas com recreação e cultura.

Destacando o item alimentação pela importância que tem no orçamento da maioria das familias, observa-se, em primeiro lugar, um aumento significativo do peso da alimentação fora do domicilio, de $2,7 \%$ para $7,1 \%$, uma mudança de hábito que reflete os efeitos da urbanização (Borges e Burman, 1992)

Como se pode verificar, em 1988 os efeitos da urbanização haviam duplicado os gastos com alimentação em restaurantes e quase duplicado, também, o consumo em cultura que participava com $4,29 \%$ do orçamento doméstico.

Mas o que chama atenção ao se observar os efeitos da urbanização sobre os hábitos de consumo do soteropolitano são as elevadas despesas com recreação $(4,1 \%)$ e educação e leitura $(4,5 \%)$, quase o dobro dos resultados encontrados na RMS para o mesmo ano 1988, o que demonstra a especificidade dos hábitos de consumo da população de Salvador.

\section{TABELA 1 - DESPESAS COM RECREAÇÃO, EDUCAÇÃO E LEITURA}

\begin{tabular}{l|c}
\hline Despesas & \% no Orçamento \\
\hline Cinema & 0,5174 \\
Ingresso para jogo & 0,1556 \\
Associação esportiva & 0,4749 \\
Discos e fitas & 0,5276 \\
Máquinafotográfica & 0,0623 \\
Acessórios fotográficos & 0,4897 \\
Aluguel de fita de vídeo & 0,1028 \\
Fita de videocassete & 0,1197 \\
Livros e revistas & 0,1306 \\
\hline Fonte: IBGE. Pesquisa de Orçamento Familiar (1988).
\end{tabular}

Esta elevada elasticidade do consumo de cultura versus urbanização permite afirmar que os hábitos de consumo da população de Salvador devem ser observados em detalhe, pois são extremamente sensíveis à estímulos externos, propagando-se a todas as camadas sociais.

Em Pesquisa Direta realizada em outubro de 1997 através da Secretaria da Cultura e Turismo da Bahia junto a 1.720 famílias residentes em Salvador, constatou-se a mudança expressiva nos hábitos de consumo do soteropolitano: os gastos com produtos e serviços culturais corresponderam a 7,96\% do orçamento, duas vezes superiores aos resultados apresentados pela pesquisa de 1988. Em 1997, entre os produtos mais consumidos pelas famílias, encontrou-se as despesas mensaiscom alimentos daculináriabaiana $(R \$ 18,20)$, discos, fitas e CDs $(R \$ 14,02)$, livros, revistas e periódicos $(\mathrm{R} \$ 8,48)$, blocos, afoxés e entidades culturais e recreativas $(\mathrm{R} \$ 6,13)$.

Comparando-se os percentuais do consumo com os da cultura entre os períodos de 1988 e 1997, verificou-se, no ano de 1997, um expressivo aumento das despesas com discos, fitas e CDs, ampliando-se quase três vezes no período analisado; também ampliou-se a participação das despesas no orçamento doméstico de livros, revistas e jornais, quase quintuplicando no período, enquanto as despesas com cinema não se alteraram, muito provavelmente substituídas pelo consumo de fitas de vídeo, item que em 1997 também triplica sua participação no orçamento do soteropolitano.

\section{Estimativa dos Rendimentos Anuais e Despesas com Cultura}

Considerando-se a massa total de rendimentos mensais da população com rendimentos, em 1996 segundo a PNAD na RMS, pode-se estimar que os rendimentos anuais sejam de aproximadamente $\mathrm{R} \$ 8,387$ bilhões, ou seja, os rendimentos mensais em doze meses de $\mathrm{R} \$ 8,055$ bilhões, adicionados aos $\mathrm{R} \$ 332,3$ milhões de recebimentos do $13^{\circ}$ salário, apenas para os ocupados com carteira assinada ou 49,5\% dos ocupados. O percentual de despesa sobre o orçamento doméstico, revelado pela Pesquisa Direta, corresponde a 7,96\%; calcula-se que aproximadamente $\mathrm{R} \$ 667,6$ milhões seriam os gastos totais com cultura na RMS, sem considerar-se a sazonalidade do consumo.

A expansão do consumo com cultura para as estimativas da Bahia levou em consideração as análises de Borges e Burman (1992), em que fora das áreas densamente urbanizadas, os percentuais de consumo de bens culturais reduzem-se à $\mathrm{m}$

hábitos de consumo alteram-se expressivamente em relação à capital, pois a oferta de serviços de recreação e cultura é muito reduzida. Dessa forma, partindo-se dos percentuais de despesa obtidos pela Pesquisa Direta em Salvador, onde são definidos quinze itens de consumo, apenas quatro itens foram considerados passíveis de consumo no meio rural, entre estes: entrada em parques, afoxés, blocos 
entidades culturais, discos e fitas, e festividades religiosas, os quais juntos somain $2,98 \%$ de despesa sobre o orçamento familiar.

TABELA 2 - DESPESA FAMILIAR MENSAL COM BENS CULTURAIS EM SALVADOR - 1997

\begin{tabular}{l|c|c}
\hline \multicolumn{1}{c|}{ Despesa Familiar } & R\$ 1,00 & $\begin{array}{c}\text { \% no Orçamento } \\
\text { Familiar }\end{array}$ \\
\hline Cinema & 4,70 & 0,44 \\
Entrada em parques & 3,86 & 0,36 \\
Teatro e centros culturais & 2,97 & 0,28 \\
Shows musicais & 5,32 & 0,49 \\
Shows de dança, teatro e circo & 0,85 & 0,08 \\
Cursos de arte & 1,02 & 0,09 \\
Museus, galerias, bibliorecas & 0,26 & 0,02 \\
Academia de dança & 2,80 & 0,26 \\
Fesividades populares/religiosas & 8,11 & 0,75 \\
Afoxés, blocos, entidades culturais e & 6,13 & 0,57 \\
recreativas & & \\
Artesanato, obras de arte, antiguidades & 2,27 & 0,21 \\
Culinária típica & 18,20 & 1,68 \\
Discos, fitas e CDs & 14,02 & 1,30 \\
Fita de video & 7,01 & 0,65 \\
Livros, revistas e periódicos & 8,48 & 0,79 \\
\hline Consumo total mensal familiar & $\mathbf{8 6 , 0 4}$ & $\mathbf{7 , 9 6}$ \\
\hline
\end{tabular}

Fonte: Secretaria da Cultura e Turismo. Bahia. Pesquisa direta, Bahia, 1997.

Na Bahia, pelos dados da PNAD de 1996, estima-se que subtraindo a massa salarial da população da RMS, resulta uma massa total de rendimentos mensais do $\mathrm{R} \$ 914,7$ milhões. Atualizando-se estes resultados e considerando-se que apenas $22 \%$ dos ocupados têm carteira assinada, segundo a PNAD, e portanto percebem $13^{\circ}$ salário, resulta em rendimentos anuais de $\mathrm{R} \$ 11,178$ bilhões, e calculando-se um percentual de gastos médio com cultura de $2,98 \%$ do orçamento doméstico para a população fora da RMS, estimam-se os gastos com cultura em aproximadamente R \$333,1 milhões. Agregando-se os gastos com cultura na RMS (R $\$ 667,6$ milhões) aos gastos na Bahia sem a RMS, obtem-se uma estimativa de consumo com cultura na Bahia de R\$1,001 bilhão em 1996.

\section{Estimativa da Sazonalidade}

$\mathrm{Na}$ Bahia, o consumo com cultura apresenta forte sazonalidade, pois é estimulado através de festas populares. Além dos números do Carnaval em Salvador, que geram aproximadamente $\mathrm{R} \$ 115$ milhões, para medir a sazonalidade deste consumo com cultura, deve-se agregar as micaretas ou carnavais fora de época e as festas juninas.

A mensuração do consumoem festas de micaretas pode ser realizada a partir das entrevistas realizadas junto à SCT e principais formadores de opinião, concluindo-se que as micaretas na Bahia, realizadas na grande maioria dos municípios, atraem um fluxo de visitantes que corresponde a aproximadamente $30 \%$ da população local. Assim contabilizada, a população exógena ou nãoresidente, que participa em micaretas durante o ano, aproxima-se de 3,7 milhões de pessoas (a população da Bahia corresponde a 12,5 milhões de habitantes). Esse fluxo de consumidores pode gerar uma despesa anual nessas festas de aproximadamente $\mathrm{R} \$ 142$ milhões (calculada como despesa por visitante a metade dos níveis de consumo/habitante durante o Carnaval de Salvador, que reúne 1,5 milhão de foliões).

Outra festa importante no calendário cultural baiano e de forte consumo sazonal são as festas juninas - São João e a de São Pedro - as quais vêm movimentando cada vez mais um fluxo muito expressivo de visitantes. Os municípios do interior do Estado têm nessas festas a grande alternativa de geração de receitas, pois a participação popular é muito forte. Embora nem todos os municípios permitam preparar um ambiente tradicional de festa do interior, capaz de atrair fluxos expressivos de visitantes, a tradição do forró e comidas típicas vêm se confirmando e orientando a festa para o meio urbano, tal como acontece no "Arraiá da Capitá", em Salvador.

Em nível de geração de receitas, os números de São João e São Pedro, segundo informações da SCT, aproximam-se aos números das micaretas. As despesas com as festas realizadas pelas prefeituras confirmam que, embora um menor número de municípios se incluam nesses festejos, a grande maioria já realizava alguma organização do evento. Também se considerou a participação da população local no consumo desta festividade, a qual supera os números das micaretas, pois eleva-se o consumo de comidas típicas, fogos, bebidas, "licores" entre outros. Diante dessas considerações os dias dedicados aos números de São João e São Pedro podem gerar consumo semelhante ao das micaretas, ou seja, o consumo de aproximadamente $\mathrm{R} \$ 142$ milhões.

Contabilizados esses consumos sazonais, realizados pelas famílias baianas, que somam R $\$ 284$ milhões de despesas realizadas em micaretas e festas juninas, bem como os R $\$ 115$ milhões no Carnaval de Salvador, concluiu-se que aproximadamente R \$ 399 milhões são consumidos sazonalmente. Agregue-se esses valores as despesas anuais com cultura de $\mathrm{R} \$ 1,001$ bilhão, tem-se que o consumo anual das famílias residentes com cultura na Bahia corresponde a $\mathrm{R} \$ 1,4$ bilhão. 
CONSUMO DAS FAMIILIAS RESIDENTES R\$1,4 bilhão

\section{Consumo do Governo e Instituições Privadas Sem Fins Lucrativos}

O consumo da administração pública, é o valor da sua produção, definida pelo Sistema de Contas Nacionais, como estrutura dos custos de produção e composta por salários e encargos, compras de bens e serviços, e consumo de capital fixo. Para a apropriação deste consumo, serão utilizados os orçamentos dos órgãos públicos, federais, estaduais e municipais ligados à produção cultural na Bahia.

\section{Esfera Estadual}

Analisado o orçamento da Secretaria da Cultura e Turismo da Bahia em 1996 , as despesas e investimentos com cultura corresponderam a $R \$ 30,9$ milhões, quando retirados os investimentos, resultou que os gastos equivaliam a aproximadamente $\mathrm{R} \$ 12,1$ milhões. Segundo essa mesma fonte, estavam destinados $\mathrm{R} \$ 18,9$ milhões para recuperação e construção de unidades culturais e recuperação c preservação do patrimônio artístico e cultural.

\section{Esfera Municipal}

Em nível de governo municipal, embora não se disponha da desagregação das rubricas correspondentes à despesa com cultura, pode-se estimar a partir dos custos da EMTURSA com o Carnaval 1996, que o consumo da prefeitura municipal de Salvador, em 1996, correspondeu a $R \$ 6,2$ milhões.

Para mensurar os gastos com cultura dos demais municípios da Bahia, optou-se pela estimativa das proporções de despesas da capital com cultura, em relação à receita da cidade, ou seja, 3,35\% (Tabela 3). Considerou-se ainda que para os demais municípios da Bahia, metade dessa proporção seria percentual mais adequado, pois também assim procedeu-se para os consumos familiares, e a grande maioria dos municípios conta com festas menos expressivas que o Carnaval. Desta forma, concluiu-se por estimar em $\mathrm{R} \$ 20,1$ milhões as despesas de consumo do governo municipal na Bahia.
TABELA 3 - PRINCIPAIS RECEITAS MUNICIPAIS NA BAHIA EM 1996

\begin{tabular}{l|c}
\hline \multicolumn{1}{|c|}{ Salvador } & Valores (RS) \\
\hline Fundo de Participação do Muricípios & 61.590 .256 \\
Cotas do ICMS & 124.056 .566 \\
\hline TOTAL Bahia & 185.646 .822 \\
\hline \multicolumn{1}{c|}{ Vundo de Participação do Muricípios } & 813.661 .458 \\
\hline Cotas do ICMS & 625.976 .326 \\
\hline TOTAL & 1.439 .637 .784 \\
\hline
\end{tabular}

Fonte: SEFAZ.

\section{Esfera Federa}

Segundo orçamento do GovernoFederal, o Ministério da Culturae o IPHAN, em 1996, realizaram uma despesa corrente e de capital na Bahia de $\mathrm{R} \$ 755$ mil.

\begin{tabular}{lll}
\hline & MUNICIPAL & R\$20,1 milhōes \\
CONSUMO & ESTADUAL & R\$ 12,1 milhöes \\
DO GOVERNO & FEDERAL & R\$ 0,8 mil \\
& TOTAL & R\$ 33,0 milhőes \\
\hline
\end{tabular}

\section{Formação Bruta de Capital Fixo do Setor Público}

\section{Esfera Estadual}

Medida sob o ângulo da absorção, esta variável corresponde ao fluxo que representa acréscimos e reposições de estoques de capital fixo (construções e equipamentos), estes dados de investimentos de acordo com o orçamento de 1996, da Secretaria da Cultura e Turismo da Bahia, corresponderam a $\mathrm{R} \$ 18,9$ milhões. 


\section{Esfera Municipal}

Os investimentos da Prefeitura de Salvador foram estimados pelas despesas de capital realizadas com o Carnaval, o que correspondeu a $R \$ 2,3$ milhões considerando-se os investimentos das demais prefeituras da Bahia segundo "proxy" realizada como proporção da despesa e receitas em Salvador, a esfera municipal teria realizado investimentos de $\mathrm{R} \$ 9,8$ milhões em 1996.

\section{TABELA 4 - CUSTOS DA EMTURSA COM O CARNAVAL 1994-1996 (RS MIL)}

\begin{tabular}{|c|c|c|c|c|}
\hline$\overline{1}$ & Item & 1994 & 1995 & 1996 \\
\hline Infra-estrutura & & $1.821,3$ & $2.132,1$ & $2.341,3$ \\
\hline Animação $^{2}$ & & $1.840,2$ & $2.022,3$ & $2.545,8$ \\
\hline Pessoal & & $1.115,7$ & $1.424,6$ & $2.301,0$ \\
\hline Operaçãa $^{3}$ & & $1.025,6$ & 998,3 & $1.327,1$ \\
\hline TOTAL & & $5.802,8$ & $6.577,3$ & $8.515,2$ \\
\hline
\end{tabular}

1. Camarotes, arquibancadas, palcos,sonorizaçāo, iluminaçāo, decoraçāo,etc.

2. Cantores, bandas, músicos, blocos, trioselétricos,minitrios,etc.

3. Logística, publicidade, fiscalizaçāo, etc.

Fonte: Casa do Carnaval ( jan/96).

\section{EsferaFederal}

Pela dificuldade de desagregação das despesas de capital e correntes, os investimentos federais foram apropriados no consumo do governo federal.

\begin{tabular}{|c|c|c|}
\hline & MUNICIPAL & RS 9.8 milhöes \\
\hline FBKF & ESTADUAL & RS 18.9 milhöes \\
\hline \multirow[t]{2}{*}{ DO GOVERNO } & FEDERAL & Apropriada em consumo \\
\hline & TOTAL & RS 28,7 milhöes \\
\hline
\end{tabular}

\section{Formação Bruta de Capital Fixo do Setor Privado}

Os investimentos privados realizados na Bahia, pelos produtores, tais como a construção de teatros, cinemas, casas de shows, artesanato, galerias podem ser estimados através de:

- A carteira de investimentos do comércio e dos serviços na Bahia, 1995-2000, apresenta US\$ 1,007 bilhão (Bahia Investimentos, julho de 1997), o que corresponde a um fluxo médio de US $\$ 167$ milhões ao ano; deste total, os investimentos em cultura deverão participar proporcionalmente ao consumo das famílias residentes e não-residentes, portantoalgumacoisa em tomo de $8 \%$, ou seja, $\mathrm{R} \$ 13,8$ milhões de novos shoppings, lojas, restaurantes, cinemas, comércio em geral;

- Outros investimentos devem ser considerados, o Carnaval de Salvador, um megaevento, que movimenta aproximadamente $\mathrm{R} \$ 115$ milhões em apenas cinco dias de festa. Os resultados dos investimentos desta festa podem ser estimados a partir dos investimentos em infra-estrutura do Carnaval de aproximadamente $\mathrm{R} \$ 2$ milhões. Os quarenta maiores blocos carnavalescos podem realizar investimentos, na montagem de um trio elétrico, que chegam a $\mathrm{R} \$ 600$ mil por bloco. Em 1996, tem-se conhecimento de compra de apenas um trio elétrico de $\mathrm{R} \$ 1,2$ milhão (Miguez de Oliveira, 1996); outros equipamentos de menor porte certamente foram adquiridos nesse ano, além de considerar-se os sessenta blocos alternativos. O resultado total se aproxima a $\mathrm{R} \$ 3,6$ milhões de investimentos.

Em 1996, estima-se que o total dos investimentos privados na Bahia corresponderiam a $\mathrm{R} \$ 17,4$ milhões e que esse montante, quando estimado para 1997, deverá estar duplicado pela grande participação dos investimentos privados no Programa Fazcultura.

A Secretaria da Cultura e Turismoda Bahia, através do ProgramaFazcultura, em 1997, aprovou $\mathrm{R} \$ 48,9$ milhões em projetos de 169 empresas que estão patrocinando atividades artístico-culturais. Esses projetos incluem pesquisa, estudos, edição de obras e a produção de atividades na área de artes cênicas, plásticas e gráficas, cinema e vídeo, fotografia, literatura, artesanato, folclore e tradições populares, museus, bibliotecas e arquivos. A lei que institui o Programa foi sancionada em dezembro de 1996, portanto esses investimentos deverão estar incluídos nas estimativas do PIB da cultura para o ano de 1997

\begin{tabular}{ll}
\hline FBKF DO SETOR PRIVADO & R\$ 17.4 milhoes \\
\hline
\end{tabular}

\section{Exportação e Importação de Serviços e Produtos Culturais}

Neste cálculo, as exportações e importações, realizadas pelo Estado da Bahia, deverão ser traduzidas segundo o conhecimento de comércio por vias internas e externas, valendo-se dos principais componentes de consumo de cultura, agora classificados como mercadorias e serviços. Entre os itens consumidos e identificados como culturais pela Pesquisa Direta, procurou-se identificar e quantificar o consumo local de produtos da cultura baiana, exceto itens como cinema, discos, revistas, fitas de vídeo, em que se encontram os itens importados de outros Estados ou países. 
Desta forma, partindo-se da análise dos itens de consumo, pode-se afirmar que a culinária típica pouco exporta e também poucas importações são realizadas. A festividades religiosas ou populares também apresentam o perfil de produção local e pouca exportaçãoe importação. Teatro, academias de dança, cursos de arte, museus, afoxés e entidades culturais são basicamente produzidos e consumidos internamente, com poucos resultados na balança comercial da Bahia.

Conquanto deva ser considerado o grande valor das obras de arte e artesanate produzidas por artistas baianos, em parte essas exportações já foram registradas como consumo dos turistas ou não-residentes. Outro ponto a consideraré a balança comercial de entrada e saída de mercadorias desse gênero, pois dificilmente seria devidamente mensurada. Neste item preferiu-se empiricamente considerar nulo o balanço de entrada e saída de mercadorias.

Através dos resultados do consumo familiar em fitas, discos, CDs, vídeos, cinema, revistas e livros, obtidos pela Pesquisa Direta, observou-se que esses produtos representam $39,9 \%$ do total de consumo de cultura, ou aproximadamente $\mathrm{R} \$ 559$ milhões. O nível de importações, nesses quatro itens de consumo pesquisados, é muito alto, pois quase não existe produção local, com exceção de parte de produção de discos, fitas, revistas, livros e jornais (Tabela 5).

TABELA 5 - PARTICIPAÇĀO DOS BENS CULTURAIS NO CONSUMO

\section{FAMILIAR NA BAHIA - 1997}

\begin{tabular}{l|c|c}
\hline \multicolumn{1}{|c|}{ Item } & $\begin{array}{c}\text { \% na Despesa com } \\
\text { Cultura }\end{array}$ & Valor (RS Mii) \\
\hline Cinema & 5,5 & $76.980,00$ \\
Discos, fitas, CD's & 16,3 & $228.200,00$ \\
Fita de vídeo & 8,2 & $114.800,00$ \\
Livros, revistas, jornais, periódicos & 9,9 & $138.600,00$ \\
\hline
\end{tabular}

Fonte: Secretaria da Cultura e Turismo.

A pesquisa qualitativa que aborda os produtores culturais e consumidores permitiu verificar que as compras de produtos vindos de fora da Bahia são realizadas principalmente pelas classes A e B. As compras são adquiridas através da Internet para diversos produtos, além de vídeos, discos, livros, revistas e quadros que são importados. Para as classes Ce Dregistraram-se as compras de discos e CDs de música internacional; filmes, revistas e jornais do sul do País (classe C).

A indústria da cultura na Bahia, especialmente a indústria fonográfica, cinematográfica e editorial é de pequeno porte e se instala lentamente no Estado. Assim a produção artística de música e literatura é industrializada essencialmente no eixo Rio-São Paulo, através das principais empresas fonográficas e editoriais, deslocando parte da geração do valor agregado da produção artística baiana para o sudeste do País.

Pode-se afirmar, segundo entrevistas realizadas em Pesquisa Direta, que a balança comercial da Bahia no tocante a livros, revistas e jornais, encontra-se próxima de zero ou pouco negativa. Embora se reconheça a dificuldade de mensurar essas contas, os royalties e direitos autorais de autores, como Jorge Amado e Ubaldo Ribeiro apenas para citar os maiores, conduzem a essas observações, além disso, no item leitura, o consumo mais comum do baiano, segundo a pesquisa, ainda é o jornal, e sua produção é essencialmente local.

O baiano consome essencialmente discos, fitas e CDs da cultura local, enquanto o nível de consumo de cultura de outros países ou Estados não ultrapassa $30 \%$. Os resultados da Pesquisa Direta registram que R $\$ 228$ milhões são gastos anualmente pelas famílias baianas na compra desses itens. Como a produção da indústria fonográfica baiana é muito reduzida, esses itens são importações especialmente vindas do eixo Rio/ São Paulo, onde se encontra a industrialização de discos. $\mathrm{O}$ valor dessas importações, consideradas a custo de fatores na produção e distribuição, permite afirmar que $30 \%$ de margens de comércio e impostos, e $12,4 \%$ de direitos autorais e artísticos são apropriados peloEstado da Bahia, tornandopossível estimar as importações em $\mathrm{R} \$ 97$ milhões.

Neste item, a exportação da produção baiana de "axé music" realiza vendas de mais de 5 milhões de discos, fitas e CDs por ano, em parte produzidos (criados) na Bahia. A venda final ao varejo dessa produção de discos pode ser estimada em $\mathrm{R} \$ 40$ milhões.

Deve-se considerar a produção industrial de discos, fitas e CDs essencialmente realizada fora da Bahia, dessa forma, analisada a composição do valor agregado da produçāo, consubstanciada em entrevistas com especialistas, observou-se que a indústria se apropria de $25 \%$ do preço final do disco, o restante do preço são margens de comércio e divulgação realizadas fora da Bahia, portanto essas exportações baianas representam apenas o valor dos direitos autorais e artísticos, algo em torno de $12,4 \%$ do valor.

Considerando-se esses indicadores, é possível estimar-se em $\mathrm{R} \$ 5$ milhões o valor das exportações de discos/ano, e o saldo da balança comercial de discos, fitas eCDs (resultado das exportações menos importações) resultaria em balança comercial negativa de $\mathrm{R} \$ 92$ milhões.

Oconsumo familiar de cinemae fitas de vídeo, dada à exiguidade da produção local, foi considerado como importações da Bahia. Dessa forma, utilizando-se os dados de consumo da Pesquisa Direta, têm-se R $\$ 192$ milhões em produtos consumidos. Para fins de cálculo de importações de mercadorias, retirou-se as margens do comércio local e os impostos indiretos (30\%), podendo-se estimarque as importações desses itens na Bahiaperfazem $\mathrm{R} \$ 134$ milhões, sendo este também o valor da balança comercial da Bahia, uma vez que se tem poucas exportações.

As exportações de shows de produtores baianos são expressivas. Segundo Miguezde Oliveira (1996) são realizadas cinqüenta festas fora da Bahia, ou mil shows 
por ano na "indústria axé". Esses valores quantificados através de pesquisas realizadas por esse mesmo autor, em que a média por apresentação de cada banda é de $\mathrm{R} \$ 23$ mil por show, podem gerar $\mathrm{R} \$ 23$ milhões por ano, conforme explicitado a seguir.

Na mesma linha de atuaçāo empresarial enquandram-se outros nomes de importância do que já é denominado de "indústria axé", tais como Netinho, a banda Asa de Águia e Ricardo Chaves. Até mesmo atraçōes de sucesso mais recentes já recebem cachês significativos. É o caso, por exemplo, da banda Eva, "que começou tocando de graça", e hoje tem um cachê médio de $R \$ 12$ mil (Aguiar et Vlad, 1995b).

Outro produto cultural de exportação, citado por Miguez de Oliveira (1996), refere-se à venda de discos. Segundo Adolfo Nery, Presidente do Conselho Municipal do Carnaval e um dos proprietários do Camaleão, "o fato é que 12 a 15 blocos carnavalescos de Salvador vendem entre quatro a cinco milhões de discos por ano".

\begin{tabular}{cl}
\hline $\begin{array}{cl}\text { EXPORTAÇŌES } \\
(-)\end{array}$ & RS 5 milhỏes (discos) + RS 23 milhỏes (shows) \\
IMPORTAÇŌES & RS 134 milhōes (cinema e video) \\
$=$ & RS 97 milhōes (discos, fitas, CD's) \\
SALDO & RS 203 milhōes \\
\hline
\end{tabular}

Recentemente alguns blocos inauguraram o sistema de franquias de suas marcas, montando filiais em várias cidades que realizam os carnavais temporões, em associação com empresários locais. Éo caso, por exemplo, do Nana Banana, presente em doze cidades, e do Cocobambu, já estabelecido em dezessete cidades.

Existem hoje, aproximadamente, mais de cinquienta carnavais fora de épocapor ano em cidades de vários Estados brasileiros, especialmente do Nordeste, muito embora cidades como Rio de Janeiro, São Paulo, Belo Horizonte e Vitória járealizem também os seus carnavais temporões, respectivamente, Rio Elétrico, Carnasampa, Carnabelôe Vital. João Pessoa, por exemplo, aonde o evento Micaroa é produzido por uma empresa privada, a Planarte, chegou a realizar a festa por duas vezes em 1995. Há a perspectiva de mais cidades serem incorporadas a esse calendário festivo, o qual já ameaça estender-se, inclusive, a países do Mercosul.

Eventos dessa natureza chegam a reunir públicos que, em alguns casos, como o Carnatal (Natal) e Fortal (Fortaleza), superam as 500 mil pessoas. O número de blocos, regra geral constituídos à imagem e semelhança dos blocos de trio baianos, já chega a 250, congregando aproximadamente $625 \mathrm{mil}$ associados. Com essa magnitude, tais eventos constituem um mercado que envolve diversos atores de porte, como a indústria hoteleira, companhias de aviação, agências de viagem e turismo, fornecedores de serviços os mais diversos (sonorização, iluminação, montagem de estruturas tubulares para camarotes, arquibancadas e palcos, segurança, etc.), indústria de confecções, comércio de alimentos e bebidas, etc., e movimentam valores bastante expressivos.

\section{Conclusāo - Impactos da Cultura no PIB da Bahia}

O ano de 1996 pode ser considerado bom para a economia baiana, que cresceu $3,9 \%$ emrelaçãoao ano anterior, o PIB, calculado pela SEI, registrouUS $\$ 34,6$ bilhões. Entre os principais vetores de crescimento, o comércio, que representa junto a hotéis e restaurantes $19,5 \%$ do PIB, obteve crescimento acima dos demais setores.

\section{TABELA 6 - ESTRUTURA DO PRODUTO INTERNO BRUTO DA BAHIA}

\begin{tabular}{l|rrr|rrrrrr}
\hline \multirow{2}{*}{ Atividade } & \multicolumn{7}{|c}{$\%$} \\
\cline { 2 - 8 } & 1990 & 1991 & 1992 & 1993 & 1994 & 1995 & 1996 \\
\hline Agricultura, silvicultura e pesca & 15,2 & 15,1 & 15,3 & 14,5 & 13,8 & 12,4 & 12,5 \\
Extrativa mineral & 3,5 & 3,4 & 3,5 & 3,2 & 3,0 & 2,9 & 2,9 \\
Indústria de Transformação & 22,3 & 22,2 & 23,2 & 24,6 & 24,7 & 24,1 & 24,2 \\
Eletricidade, água, utilidades & 3,7 & 4,1 & 4,3 & 4,3 & 4,0 & 3,7 & 3,5 \\
Construção & 2,4 & 2,3 & 2,3 & 2,3 & 2,4 & 2,4 & 2,4 \\
Comércio, restaurantes e hotéis & 19,6 & 18,2 & 16,8 & 15,9 & 17,4 & 19,0 & 19,5 \\
Transportes, arm. e comunicaçōes & 7,2 & 7,6 & 7,6 & 7,7 & 7,8 & 8,5 & 8,5 \\
Estab. fin., segur. e bens imóveis & 14,4 & 14,7 & 14,3 & 14,5 & 14,1 & 14,2 & 14,1 \\
Serviços comunitários e sociais & 11,7 & 12,4 & 12,7 & 12,9 & 12,8 & 12,8 & 12,4 \\
\hline
\end{tabular}

Fonte: Superintendência de Estudos Econômicos e Sociais da Bahia (SEI)

A cultura definida como consumo e investimento de produtos, de arte, shows, espetáculos, discos, livros, cursos, museus, teatros, obteve um PIB, contabilizado comodispêndiototal em dólares, equivalente a US $\$ 1,484$ bilhão para o ano de 1996, comparativamente ao PIB do Estado, participou com 4,3\%, superior a toda indústria extrativa mineral e à construção, mas a grande importância da cultura na economia não está medida no seu valor contábil, e sim na geração de empregos, o responsável por 7,2\% das ocupações na RMS. 
TABELA 7 - PIB DA CULTURA NA BAHIA. ESTIMATIVA DOS COMPONENTES DE DESPESA EM 1996

\begin{tabular}{lc}
\hline \multicolumn{1}{c}{ Especificação } & RS milhóes de 1996 \\
\hline CONSUMOFINAL & $1.645,00$ \\
Consumo final das familias & $1.612,00$ \\
Residentes & $1.400,00$ \\
Não-residentes & 212,00 \\
Consumo final das administrações públicas & 33,00 \\
Municipal & 20,10 \\
Estadual & 12,10 \\
Federal & 0,80 \\
FORMAÇÃOBRUTADECAPITALFIXO & 46,10 \\
FBKF do Governo & 28,70 \\
Municipal & 9,80 \\
Estadual & 18,90 \\
Federal & $\ldots$ \\
FBKF do Setor Privado & 17,40 \\
VARIAÇÃO DE ESTOQUES' & $\ldots$ \\
EXPORTAÇÕESDEBENSESERVIÇOS & 28,00 \\
IMPORTAÇÕESDEBENSESERVIÇOS & $(231,00)$ \\
\hline PIBDACULTURAEMR $\$$ & $\mathrm{R} \$ 1.488,00$ \\
PIBDACULTURAEMUS $\$ 2$ & US $\$ 1.479,45$ \\
PARTICIPAÇÃONOPIBDABAHIA & $4,3 \%$ \\
\hline
\end{tabular}

1. A variação de estoques de serviçosculturais não existe, os estoques de bensculturais tais como discos, livros etc., não puderam ser mensurados.

2. O PIB em dólares é resultado da variação cambial utilizada pela SEI, em que o PIB $\mathrm{R} \$ 34,8$ bilhões e PIB US $\$ 34,6$ bilhões.

A cultura, como produto de exportação, é difusora dos atrativos da Bahia.Em virtude da imagem positiva da nossa música e do acervo arquitetônico do Centro Histórico restaurado, criou-se a sustentabilidade do desejo de melhoria social. Os resultados dessa boa imagem internacional já podem ser observados nos investimentos externos na Bahia, cuja captação já é superior à média nacional.

Realimenta-se um processo de desenvolvimento, agora equilibrado pelos investimentos produtivos, em que o Estado leva a toda população o direito à música e arte, onde a cultura pode ser vista por todos.

\section{BIBLIOGRAFIA}

BAHIATURSA. 1997. Indicadores básicos do turismo baiano. Desempenho do turismo baiano 1990/1996. Salvador: Bahiatursa, junho

1996 Balanco geraldo Estado/96 Salvador: Secretariada Fazenda

BORGES, Angela e BURMAN Grazia. 1992. Mudanças na despesa familiar ém Salvador entre 1974 e $1987 / 88$. Salvador: SEI (Série Especiais SEI)

BURMAN, Grazia e GUIMARĀES, José Ribeiro. 1997. A geraçāo de empregos na Bahia. Salvador, n.2, julho. BRASIL não pára no Carnaval. 1997. Folha de S. Paulo, 2 fev.

列 obra turistica em Salvador. Salvador.

GUIMARAES, José Ribeiro. 1997. Distribuição dos rendimentos na RMS. Conjuntura e Planejamento, Salvador, n.33, fev.

NSTITUTO BRASILEIRO DE GEOGRAFIA E ESTATÍSTICA. 1990. Sistemas de contas nacionais consolidadas Brasil. Rio de Janeiro: IBGE. Vol. 8 (Série Relatórios Metodológicos).

MENEZES, Wilson Fittipaldi. 1997. Perfil do desempregado na RMS. Conjuntura e Planejamento, Salvador, n. 39, ago. MIGUEZ DE OLIVEIRA, Paulo César. 1996. Carnaval baiano: as tramas da alegria e a teia de negócios. Salvador:

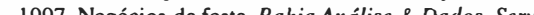
TECRETARIADA CULTURA ETURISMODABA

NSTITUTO BRASILEIRO DE GEOGRAFIA EESTATÍSTICA. Rio de Janeiro. 1988. Pesquisa de orçamento familiar.

Recebido em 10/6/98

Aprovado em 30/7/98 